Eka Diah Kartiningrum, Perilaku Makan dengan Kejadian...

\title{
PERILAKU MAKAN DENGAN KEJADIAN HIPERTENSI PADA LANSIA DI DESA GAYAMAN MOJOANYAR MOJOKERTO
}

\author{
Eka Diah Kartiningrum \\ Dosen pengajar prodi D3 Keperawatan Sekolah Tinggi Ilmu Kesehatan Majapahit \\ E-mail: ekadiahkartiningrum@gmail.com
}

\begin{abstract}
Abstrak
Hipertensi pada lansia adalah penyakit yang ditandai dengan adanya peningkatan tekanan darah secara terus menerus pada lansia. Hipertensi disebabkan karena banyak faktor diantaranya adalah perilaku makan. Tujuan penelitian ini adalah untuk menganalisis hubungan perilaku makan dengan kejadian hipertensi pada lansia. Penelitian ini menggunakan desain crossectional dengan kelompok usia lanjut sebagai populasi, sebanyak 33 orang diambil sebagai sampel. Data perilaku makan dikumpulkan menggunakan teknik wawancara sedangkan kejadian hipertensi ditentukan berdasarkan pengamatan terhadap tekanan darah menggunakan tensimeter. Hasil penelitian kemudian dianalisa menggunakan uji regresi logistik. Hasil penelitian menunjukkan bahwa sebanyak 54,5\% responden memiliki perilaku makan yang tidak baik dalam hidupnya, sedangkan $60,6 \%$ responden dinyatakan mengalami hipertensi. Hasil regresi logistik menunjukkan bahwa perilaku makan sangat mempengaruhi kejadian hipertensi. Orang usia lanjut yang memiliki perilaku makan yang tidak baik memiliki resiko mengalami hipertensi 5,25 kali lebih besar dibandingkan lanjut usia dengan perilaku makan yang baik. Perilaku makan menentukan asupan gizi yang terserap dalam tubuh manusia. Menu makanan yang mengandung tinggi garam, tinggi lemak dan rendah serat menyebabkan gangguan stabilitas kadar natrium dan kalium dalam tubuh sehingga berdampak pada peningkatan tekanan darah. Oleh sebab itu keluarga hendaknya melakukan pengaturan perilaku makan mulai dari penataan menu, frekuensi dan jumlah konsumsi pangan tingkat keluarga agar seluruh anggota keluarga dapat melewati masa lanjut usia dengan baik.
\end{abstract}

Kata kunci: hipertensi, perilaku, makan, lansia

\begin{abstract}
Hypertension in the elderly is a disease characterized by an increase in blood pressure continuously. Hypertension is caused by many factors such as eating behavior. The purpose of this study was to analyze the effect of eating behavior to the incidence of hypertension in the elderly. This study used crossectional design with elderly group as population, as many as 33 orsng was taken as sample. The data of eating behavior was collected by using interview technique while hypertension incidence was determined based on observation of blood pressure by using tensimeter. The results then analyzed by using logistic regression test. The results showed that as many as $54.5 \%$ of respondents have bad eating behavior, while $60.6 \%$ of respondents expressed hypertension. Logistic regression results show that eating behavior greatly affects the incidence of hypertension. Elderly people who have bad eating behavior have a risk of hypertension 5.25 times greater than the elderly with good eating behavior. Eating behavior determines the intake of nutrients absorbed in the human body. Foods that contain high salt, high fat and low fiber cause stability disorders sodium and potassium levels in the body so that the impact on the increase in blood pressure. Therefore, the family should make the setting of eating behavior ranging from the arrangement of the menu, the frequency and amount of food consumption family level so that all family members can pass through the elderly with both.
\end{abstract}

Keyword:hypertension, habit, eating, elderly

\section{PENDAHULUAN}

Hipertensi adalah penyakit degenaratif yang ditandai dengan terjadinya peningkatan tekanan darah sampai melebihi batas normal
(Bustan, 2000). Tekanan darah normal adalah 140/90 mmHg (Reeves, 2001 dalam Manurung 2016). Kejadian hipertensi pada lanjut usia akan meningkatkan resiko terjadinya beberapa 
penyakit berbahaya penyebab kematian, seperti penyakit jantung koroner dan stroke (Indah, 2014). Komplikasi jangka panjang tekanan darah tinggi berupa stroke, penyakit ginjal, gagal jantung, katarak (Smeltzer, Susanne C, Bare, Brebda G, 2002).

Hasil data dari profil kesehatan Kabupaten Mojokerto tahun 2015 menyatakan bahwa hipertensi di Kabupaten Mojokerto yang didapatkan melalui pengukuran pada usia kurang dari 18 tahun didapatkan sebanyak 46.981 jiwa yang mengalami hipertensi dari total 772.697 jiwa.Hasil survey pada kegiatan posyandu lansia di Dusun Tambak rejo Desa Gayaman Mojoanyar Mojokerto pada tanggal 7 Februari 2018 di dapatkan kasus hipertensi pada lansia sebanyak 15 orang $(60 \%)$ dari total lansia yang hadir di Posyandu lansia.

Faktor-faktor yang mempengaruhi hipertensi adalah umur yang semakin tua, riwayat keluarga dengan hipertensi, kebiasaan mengkomsumsi makanan asin, tidak biasa berolahraga, obesitas, jenis kelamin, kebiasaan merokok, kebiasaan minum-minuman yang beralkohol dan stres kejiwaan (Gunawan, 2008). Pola makan yang salah merupakan salah satu faktor resiko yang meningkatkan penyakit hipertensi. Faktor makanan modern sebagai penyumbang utama terjadinya hipertensi. Kelebihan asupan lemak dalam tubuh meningkat, terutama kolestrol yang menyebabkan kenaikan berat badan sehingga volume darah mengalami peningkatan tekanan yang lebih besar (Ramayulis, 2010).

Penelitian Rawasiah (2014) tentang hubungan faktor konsumsi makanan dengan kejadian hipertensi pada lansia Di Puskesmas Pattingalloang menunjukkan bahwa ada hubungan antara konsumsi makanan asin dengan kejadian hipertensi pada lansia, sedangkan variabel antara konsumsi makanan manis $(p=0,416)$ dan konsumsi makanan berlemak $(p=0,303)$ tidak ada hubungan dengan kejadian hipertensi pada lansia.

Penatalaksanaan dan perawatan hipertensi pada lanjut usia memerlukan pendekatan tersendiri dan pemahaman yang lebih baik tentang patofisiologinya. Perlindungan pertama yang terbaik untuk mengatasi kerusakan pembuluh darah akibat hipertensi adalah dengan mencegahnya, dan perlindungan kedua yang terbaik adalah dengan mengontrolnya secara rutin. Selain itu, penting sekali support atau dukungan keluarga psikososial dari berbagai pihak khususnya keluarga yang merupakan orang yang paling dekat dengan lanjut usia khususnya mengenai penataan menu makan dalam sehari-hari (Zulfitri, 2013). Berdasarkan penjelasan pada latar belakang diatas maka peneliti tertarik untuk melakukan penelitian dengan judul pengaruh perilaku makan terhadap kejadian hipertensi pada lansia di Desa Gayaman Kecamatan Mojoanyar Mojokerto.

\section{METODE PENELITIAN}

Penelitian ini menggunakan desain observasional dengan pendekatan crossectional. Populasi penelitian adalah seluruh lansia yang aktif melaksanakan posyandu lansia di Desa Gayaman sebanyak 58 orang dengan sampel sebanyak 33 orang yang diambil dengan teknik 
Eka Diah Kartiningrum, Perilaku Makan dengan Kejadian...

simple random sampling. Data perilaku makan dikumpulkan menggunakan teknik wawancara sedangkan kejadian hipertensi diukur berdasarkan tekanan darah yang diukur menggunakan tensimeter. Untuk mengetahui pengaruh perilaku makan terhadap kejadian hipertensi dilakukan uji regresi logistik.

\section{HASIL PENELITIAN}

\section{Data umum}

Tabel 1 Distribusi Frekuensi Responden Berdasarkan Usia Lansia Di Desa Gayaman Mojoanyar Mojokerto

\begin{tabular}{lccc}
\hline No & Usia & Frekuensi & Persentase \\
\hline 1 & $45-49$ tahun & 10 & 30 \\
\hline 2 & $50-54$ tahun & 9 & 27 \\
\hline 3 & $55-59$ tahun & 9 & 27 \\
\hline 4 & $60-64$ tahun & 1 & 3 \\
\hline 5 & $65-69$ tahun & 4 & 13 \\
\hline & Total & 33 & 100 \\
\hline
\end{tabular}

Berdasarkan data diatas dapat diketahui bahwa paling banyak responden berusia 45-49 tahun sedangkan responden yang berumur 60-64 tahun memiliki proporsi yang paling sedikit.

Tabel 2 Distribusi Frekuensi Responden Berdasarkan Tingkat Pendidikan Lansia Di Desa Gayaman Mojoanyar Mojokerto

\begin{tabular}{llcc}
\hline No & $\begin{array}{l}\text { Tingkat } \\
\text { Pendidikan }\end{array}$ & Frekuensi & Persentase \\
\hline 1 & Tidak sekolah & 16 & 48.5 \\
\hline 2 & SD & 9 & 27.3 \\
\hline 3 & SMP & 6 & 18.2 \\
\hline 4 & SMU & 2 & 6.1 \\
\hline 5 & PT & 0 & 0 \\
\hline \multicolumn{2}{r}{ Total } & 33 & 100 \\
\hline
\end{tabular}

Tabel 2 menjelaskan bahwa hampir setengah responden tidak sekolah, dan tidak ada responden yang lulusan Perguruan Tinggi.

Tabel 3 Distribusi Frekuensi Responden Berdasarkan Jenis Kelamin Lansia
Di Desa Gayaman Mojoanyar Mojokerto

\begin{tabular}{cccc}
\hline No & Jenis Kelamin & Frekuensi & Persentase \\
\hline 1 & Laki-laki & 10 & 30.3 \\
\hline 2 & Perempuan & 23 & 69.7 \\
\hline & Total & 33 & 100 \\
\hline
\end{tabular}

Tabel 3 menjelaskan bahwa lebih dari setengah responden berjenis kelamin perempuan sedangkan sisanya berjenis kelamin laki-laki.

\section{Data khusus}

Tabel 4 Distribusi Frekuensi Responden Berdasarkan Perilaku Makan Lansia Di Desa Gayaman Mojoanyar Mojokerto

\begin{tabular}{lccc}
\hline No & $\begin{array}{l}\text { Perilaku } \\
\text { Makan }\end{array}$ & Frekuensi & Persentase \\
\hline 1 & Baik & 15 & 45.5 \\
\hline 2 & Tidak Baik & 18 & 54.5 \\
\hline & Total & 33 & 100 \\
\hline
\end{tabular}

Tabel 4 menjelaskan bahwa lebih dari separuh responden memiliki perilaku makan yang tidak baik yang berarti responden sangat menyukai makanan tinggi natrium, tinggi lemak dan tidak menyukai sayuran yang berwarna hijau. Konsumsi buah dan minum air putih juga kurang dari normal.

Tabel 5 Distribusi Frekuensi Responden Berdasarkan Kejadian Hipertensi Pada Lansia Di Desa Gayaman Mojoanyar Mojokerto

\begin{tabular}{llcc}
\hline No & $\begin{array}{l}\text { Kejadian } \\
\text { Hipertensi }\end{array}$ & Frekuensi & Persentase \\
\hline 1 & $\begin{array}{l}\text { Tidak } \\
\text { hipertensi }\end{array}$ & 13 & 39.4 \\
\hline 2 & Hipertensi & 20 & 60.6 \\
\hline & Total & 33 & 100 \\
\hline
\end{tabular}

Tabel 5 menjelaskan bahwa lebih dari separuh responden mengalami hipertensi sedangkan sisanya tidak menderita hipertensi.

Tabel 6 Hasil Analisis Pengaruh Perilaku Makan Terhadap Kejadian 
Hipertensi Pada Lansia Di Desa Gayaman Mojoanyar Mojokerto

\begin{tabular}{llcc}
\hline No & $\begin{array}{l}\text { Variabel } \\
\text { independen }\end{array}$ & $\operatorname{Exp}(\beta)$ & pvalue \\
\hline 1 & Perilaku Makan & 5.250 & 0.032 \\
\hline 2 & Konstanta & 0.127 & 0.085 \\
\hline & Hasil analisis & regresi & logistik
\end{tabular}
menjelaskan bahwa perilaku makan lansia yang diukur berdasarkan riwayat keseharian menunjukkan adanya pengaruh yang signifikan terhadap penentuan kejadian hipertensi pada lansia. Lansia dengan riwayat perilaku makan yang tidak baik memiliki resiko mengalami hipertensi 5,25 kali lebih besar dibandingkan responden yang memiliki riwayat perilaku makan yang baik. Selain itu nilai Rsquare menunjukkan 19\% yang berarti bahwa 19\% kejadian hipertensi yang terjadi pada diri seseorang ditentukan oleh perilaku makan seseorang.

\section{PEMBAHASAN}

Menurut Nicholson (2007) Garam khususnya ion Natrium akan diserap oleh tubuh dan masuk ke dalam pembuluh darah, sehingga konsentrasi ion natrium dalam darah akan meningkat. Sedangkan ion Natrium tersebut mempunyai sifat retensi air (menahan air), sehingga menyebabkan volume darah menjadi naik dan hal ini secara otomatis menyebabkan tekanan darah menjadi naik, dan jika kadar garam dalam darah meningkat, tubuh akan berusaha menetralkannya, yaitu mengencerkannya dengan air. Hal ini terjadi melalui dua mekanisme yaitu, kadar garam yang tinggi dalam darah akan merangsang pusat haus di otak, sehingga seseorang akan minum lebih banyak air. Dan kadar garam yang tinggi juga akan menyebabkan pelepasan hormon antidiuretik, yaitu hormon yang menyebabkan ginjal menyerap kembali sebagian besar air yang telah disaringnya, sebelum dikeluarkan menjadi air kemih. Masuknya air dalam jumlah besar ke dalam pembuluh darah menyebabkan volume darah yang ada dalam sistem peredaran darah bertambah. Akibatnya, tekanan darah meninggi.

Kajian eksperimental dan pengamatan menujukkan bahwa asupan natrium klorida yang melebihi kebutuhan fisiologis bisa menimbulkan hipertensi. Hipertensi hampir tidak ditemukan pada golongan suku bangsa yang konsumsi garamnya minimal, apabila asupan garam kurang 3 gram/hari, maka prevalensi hipertensi hanya beberapa persen saja, tetapi bila asupan antara 5-15 gram/hari, maka prevalensi akan naik menjadi 15-20\%.

Konsumsi natrium yang berlebih menyebabkan konsentrasi natrium di dalam cairan ekstraseluler meningkat. Untuk menormalkannya, cairan intraseluler ditarik ke luar, sehingga volume cairan ekstraseluler meningkat. Meningkatnya volume cairan ekstraseluler tersebut menyebabkan meningkatnya volume darah, sehingga berdampak kepada timbulnya hipertensi.

Konsumsi garam dapur yang dianjurkan tidak lebih dari 2.300 gram per hari, setara dengan satu sendok teh. Dalam kenyataannya, konsumsi berlebih karena budaya masakmemasak masyarakat kita yang umumnya boros menggunakan garam. Indra perasa kita sejak kanak-kanak telah dibiasakan untuk 
Eka Diah Kartiningrum, Perilaku Makan dengan Kejadian...

memiliki ambang batas yang tinggi terhadap rasa asin, sehingga sulit untuk dapat menerima makanan yang agak tawar.Jika kadar garam dalam darah meningkat, tubuh akan berusaha menetralkannya, yaitu mengencerkannya dengan air. Hal ini terjadi melalui dua mekanisme yaitu : kadar garam yang tinggi dalam darah akan merangsang pusat haus di otak, sehingga seseorang akan minum lebih banyak air; kadar garam yang tinggi juga akan menyebabkan pelepasan hormon antidiuretik, yaitu hormon yang menyebabkan ginjal menyerap kembali sebagian besar air yang telah disaringnya, sebelum dikeluarkan menjadi air kemih.Masuknya air dalam jumlah besar ke dalam pembuluh darah menyebabkan volume darah yang ada dalam sistem peredaran darah bertambah. Akibatnya, tekanan darah meninggi

Oleh karena itu, pada penderita hipertensi, membatasi garam sangat penting. Batas konsumsi garam yang dianjurkan American Heart Association tidak lebih dari 2.300 gr perhari (sebagai perbandingan, satu sendok teh mengandung sekitar 2.400 gr garam) (Nicholson CR, 2007).

Selain makanan yang tinggi garam, konsumsi tinggi lemak yang dilakukan responden dapat memicu terjadinya hipertensi.Konsumsi lemak secara berlebihan akan meninkatkan kadar kolesterol dan trigliserida, kadar kolesterol darah yang tinggi dapat mengakibatkan adanya endapan kolesterol dalam dinding pembuluh darah. Lama-kelamaan, jika endapan kolesterol bertambah akan menyumbat pembuluh nadi dan mengganggu peredaran darah. Dengan demikian, akan memperberat kerja jantung dan secara tidak langsung menyebabkan peningkatan tekanan darah.

Selain makanan tinggi garam, konsumsi lemak juga mempengaruhi terjadinya hipertensi pada lansia. Lemak yang berhubungan erat dengan hipertensi adalah: kolesterol LDL (low density lipoprotein), kolesterol HDL (high density lipoprotein), dan triglisida.Membatasi makanan yang tinggi lemak dan kolesterol antara lain: semua jeroan, kuning telur, ayam terutama ayam potong (terutama bagian kepala, kaki, ekor, kulit, dan sayap), otak, udang, cumi, kepiting, kerang, dan semua makanan yang dimasak dengan minyak goreng, margarin, maupun keju. Lemak dengan kolesterol akan membentuk plak dalam arteri dan akan mengeraskannya. Lipid harus diperiksa secara teratur dan di jaga agar senantiasa berada dalam batas normal (Arora, 2008).

\section{KESIMPULAN}

Hasil penelitian dapat disimpulkan bahwa riwayat perilaku makan sangat berpengaruh terhadap kejadian hipertensi pada lansia. Lansia yang memiliki riwayat perilaku makan seharihari yang tidak baik memiliki resiko 5,25 kali lebih besar mengalami hipertensi dibandingkan yang memiliki perilaku makan baik. Pengaturan perilaku makan sejak dini sangat penting lansia, oleh sebab itu keluarga harus memahami pengaturan makanan seimbang dan mampu mengatur dan mengelola perilaku makan keluarga agar kebutuhan gizi seluruh anggota keluarga dapat terpenuhi. Sehingga 
Jurnal Keperawatan Malang (JKM), Volume 3, Nomor 1, Juni 2018 1-6

anggota keluarga dapat menjalani masa lanjut usia dengan lebih berkualitas dan sehat.

\section{DAFTAR RUJUKAN}

Arora, Anjali, 2008. 5 langkah Mencegah dan Mergobati Tekanan Darah Tinggi, Jakarata : Bhuana Ilmu Populer.

Bustan, 2000. Epidemologi Penyakit Tidak Menular. Jakarta : Rineka Cipta.

Gunawan, Lany. 2008. Hipertensi Tekanan Darah Tinggi, Yogyakarta : Kanisius.

Indah, Y. 2014. Hipertensi bukan untuk ditakuti. Jakarta selatan: FMedia

Manurung, WP., Wibowo, A., 2016. Konsumsi Semangka Untuk Menurunkan Tekanan Darah pada Penderrita Hipertensi. MAJORITY. Vol 5 No 5 Desember 2016. Hal: 102-107 dalam http://juke.kedokteran.unila.ac.id/inde x.php/majority/article/view/932/765

Nicholson, CR. Cleveland, Clinic 2007 . Less Sodium, Lower Blood Pressure, High Blood Pressure and Nutrition, http://www.wartamedika.com/" title=" hipertensi mengapa tak boleh makan. html. diakses tanggal 10 Januari 2009.

Ramayulis, R 2010, Menu dan resep untuk penderita hipertensi, Jakarta : Penebar Plus

Rawasiah A.B., Wahiduddin., Rismayanti., 2014. Hubungan Faktor Konsumsi Makanan Dengan Kejadian Hipertensi Pada Lansia di Puskesmas Pattingallong.http://repository.unhas.a c.id/bitstream/handle/123456789/1083

6/A.BESSE\%20RAWASIAH\%20M. \%20MAPPAGILING\%20K11112616. pdf? sequence $=1 \quad$ (Jurnal online. Diakses pada tanggal 21 Agustus 2015).

Smeltzer, Susanne C, Bare, Brebda G, 2002. Buku Ajar Keperawatan Medikal Bedah, Jakarta: Penerbit Buku Kedokteran EGC.

Sudoyo, Aru, W, Dkk. 2006. Ilmu Penyakit dalam Jilid I , Edisi IV, Jakarta : Pusat Penerbitan Ilmu Penyakit dalam FKUI.

Zulfitri, 2013 Hubungan dukungan keluarga dengan perilaku lanjut usia hipertensi dalam mengontrol kesehatannya di wilayah kerja puskesmas Melur Pekanbaru. Tesis FIK UI Jakarta. 